ARTICLE

DOI: $10.1038 / s 41467-018-07075-3$

\title{
Photoreduction of gaseous oxidized mercury changes global atmospheric mercury speciation, transport and deposition
}

\author{
Alfonso Saiz-Lopez (10 1, Sebastian P. Sitkiewicz ${ }^{2,3}$, Daniel Roca-Sanjuán ${ }^{3}$, Josep M. Oliva-Enrich1, \\ Juan Z. Dávalos ${ }^{1}$, Rafael Notario ${ }^{1}$, Martin Jiskra (i) ${ }^{4}$, Yang Xu ${ }^{4}$, Feiyue Wang (1) ${ }^{5}$, Colin P. Thackray (1) ${ }^{6}$,

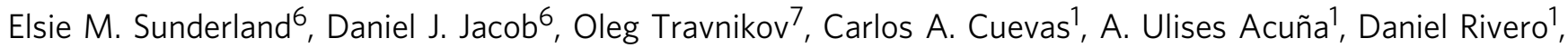 \\ John M.C. Plane ${ }^{8}$, Douglas E. Kinnison ${ }^{9}$ \& Jeroen E. Sonke 4
}

Anthropogenic mercury $(\mathrm{Hg}(0)$ ) emissions oxidize to gaseous $\mathrm{Hg}(\mathrm{II})$ compounds, before deposition to Earth surface ecosystems. Atmospheric reduction of $\mathrm{Hg}(\mathrm{II})$ competes with deposition, thereby modifying the magnitude and pattern of $\mathrm{Hg}$ deposition. Global $\mathrm{Hg}$ models have postulated that $\mathrm{Hg}(\mathrm{II})$ reduction in the atmosphere occurs through aqueous-phase photoreduction that may take place in clouds. Here we report that experimental rainfall $\mathrm{Hg}(\mathrm{II})$ photoreduction rates are much slower than modelled rates. We compute absorption cross sections of $\mathrm{Hg}(\mathrm{II})$ compounds and show that fast gas-phase $\mathrm{Hg}(\mathrm{II})$ photolysis can dominate atmospheric mercury reduction and lead to a substantial increase in the modelled, global atmospheric $\mathrm{Hg}$ lifetime by a factor two. Models with $\mathrm{Hg}(\mathrm{II})$ photolysis show enhanced $\mathrm{Hg}$ (0) deposition to land, which may prolong recovery of aquatic ecosystems long after $\mathrm{Hg}$ emissions are lowered, due to the longer residence time of $\mathrm{Hg}$ in soils compared with the ocean. Fast $\mathrm{Hg}(\mathrm{II})$ photolysis substantially changes atmospheric $\mathrm{Hg}$ dynamics and requires further assessment at regional and local scales.

\footnotetext{
${ }^{1}$ Department of Atmospheric Chemistry and Climate, Institute of Physical Chemistry Rocasolano, CSIC, Madrid 28006, Spain. ${ }^{2}$ Kimika Fakultatea, Euskal Herriko Unibertsitatea UPV/EHU and Donostia International Physics Center (DIPC), P.K. 1072, Euskadi, 20080 Donostia, Spain. ${ }^{3}$ Institut de Ciencia Molecular, Universitat de Valencia, Valencia 46071, Spain. ${ }^{4}$ Géosciences Environnement Toulouse, CNRS/OMP/Université de Toulouse, 31400 Toulouse, France. ${ }^{5}$ Department of Environment and Geography, Centre for Earth Observation Science, University of Manitoba, Winnipeg, MB R3T 2N2, Canada. ${ }^{6}$ Harvard John A. Paulson School of Engineering and Applied Sciences, Harvard University, Cambridge, MA 02138, USA. ${ }^{7}$ Meteorological Synthesizing Centre - East of EMEP, Moscow 115419, Russia. ${ }^{8}$ School of Chemistry, University of Leeds, Leeds LS2 9JT, UK. ${ }^{9}$ Atmospheric Chemistry Observations and Modelling, NCAR, Boulder, CO 80301, USA. Correspondence and requests for materials should be addressed to A.S.-L. (email: a.saiz@csic.es)
} 
A tmospheric mercury, a contaminant of global concern, is primarily emitted in the gaseous elemental $\mathrm{Hg}(0)$ form, with smaller contributions of gaseous oxidized $\mathrm{Hg}$ (II) and particle-bound $\mathrm{Hg}(\mathrm{II})^{1,2}$. Gaseous oxidized $\mathrm{Hg}(\mathrm{II}) \mathrm{XY}$ compounds may contain a variety of $\mathrm{X}, \mathrm{Y}$ halogen atoms or oxygen-containing species, including $\mathrm{Br}, \mathrm{BrO}, \mathrm{Cl}, \mathrm{I}, \mathrm{O}, \mathrm{OH}, \mathrm{HO}_{2}, \mathrm{NO}_{2}$, and organic groups. Due to the low ambient concentration $\left(\mathrm{pg} \mathrm{m}^{-3}\right)$, gaseous oxidized $\mathrm{Hg}(\mathrm{II})$ compounds have only been identified as $\mathrm{HgCl}_{2}$ and $\mathrm{HgBr}_{2}$ in urban and indoor air ${ }^{3}$ and as $\mathrm{HgCl}_{2}$ in power plant plumes ${ }^{4}$. The atmospheric $\mathrm{Hg}(0)$ and $\mathrm{Hg}(\mathrm{II})$ forms have markedly different water solubility, chemical reactivity and lifetime against deposition. The lifetime of $\operatorname{Hg}(0)$ against deposition is in the range of several months to over a year, whereas that of $\mathrm{Hg}$ (II) compounds is on the order of days to weeks ${ }^{5}$. Eventually, $\mathrm{Hg}(0)$ is oxidized to $\mathrm{Hg}$ (II) compounds, which are soluble, partition into aerosol, and deposit readily both by dry and wet mechanisms. Direct assimilation of $\mathrm{Hg}(0)$ by plants and oceans is also thought to be important ${ }^{6,7}$. The long lifetime of $\mathrm{Hg}(0)$ leads to $\mathrm{Hg}$ deposition far from its emission sources to remote ecosystems, including the open oceans and polar regions. In aquatic ecosystems, $\mathrm{Hg}$ (II) is methylated and may be biomagnified up the food chain to levels that induce toxic effects in wildlife and humans ${ }^{8}$.

The development of atmospheric chemistry and transport models (CTMs), an important tool for understanding global $\mathrm{Hg}$ cycling and predicting future $\mathrm{Hg}$ exposure, has drawn much attention to the mechanistic aspects of $\mathrm{Hg}(0)$ oxidation. While gasphase $\mathrm{O}_{3}, \mathrm{OH}, \mathrm{HO}_{2}, \mathrm{H}_{2} \mathrm{O}_{2}$, and $\mathrm{NO}_{3}$ are all potential $\mathrm{Hg}(0)$ oxidants $^{6,9-11}$, the oxidation process under atmospheric conditions is thought to be initiated primarily via photolytically produced

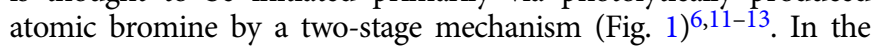
first step, the dominant reaction to produce gaseous oxidized $\mathrm{Hg}$ (II) compounds is thought to be the oxidation of $\mathrm{Hg}(0)$ by bromine atoms, yielding the unstable intermediate $\mathrm{HgBr}$. This radical can be readily dissociated back to $\mathrm{Hg}(0)$, but $\mathrm{HgBr}$ can also be competitively oxidized by other major radical oxidant species in the atmosphere (e.g. $\mathrm{OH}, \mathrm{Br}, \mathrm{I}, \mathrm{Cl}, \mathrm{NO}_{2}, \mathrm{HO}_{2}, \mathrm{BrO}, \mathrm{IO}$, and $\mathrm{ClO}$ ) to a series of currently-assumed stable $\mathrm{Hg}(\mathrm{II})$ compounds, as shown in Fig. 1:

Much less is known about the reduction of $\mathrm{Hg}$ (II) compounds to $\mathrm{Hg}(0)$ in the atmosphere. Global $\mathrm{Hg}$ CTMs, based on $\mathrm{Hg}(0)$ oxidation alone, predict an unrealistically short residence time of $\mathrm{Hg}(0)$, and the simulated spatiotemporal $\mathrm{Hg}(0)$ variations would not match observations ${ }^{6}$. To reconcile such differences, these models need to include an adjustable term to account for $\mathrm{Hg}$ (II) reduction in the atmosphere. Such reduction has been presumed to occur in the aqueous phase of clouds ${ }^{6,10,14}$. Faster gas-phase $\mathrm{Hg}(0)$ oxidation kinetics has led to the need of these models to employ ever faster in-cloud $\mathrm{Hg}(\mathrm{II})$ reduction ${ }^{6}$, with maximum rate constants $>\sim 1-3 \mathrm{~h}^{-1}$, corresponding to in-cloud $\mathrm{Hg}$ (II) lifetimes $<1 \mathrm{~h}$ on a global mean basis (see SI). Although aqueous $\mathrm{Hg}(\mathrm{II})$ photoreduction in Earth's surface waters is a welldocumented process ${ }^{15}$, little experimental or observational evidence exists in the case of atmospheric liquid water ${ }^{16}$. Earlier

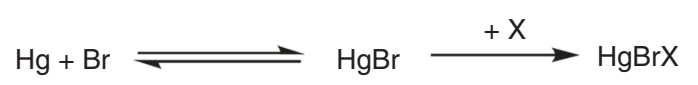

$$
X=\mathrm{OH}, \mathrm{Cl}, \mathrm{Br}, \mathrm{I}, \mathrm{NO}_{2}, \mathrm{HO}_{2}, \mathrm{ClO}, \mathrm{BrO}, \mathrm{IO}
$$

$$
\mathrm{Hg}+\mathrm{Cl}_{2} \longrightarrow \mathrm{HgCl}_{2}
$$

Fig. 1 Current understanding of the formation of oxidized $\mathrm{Hg}$ (II) compounds from atmospheric gaseous elemental mercury initiated by different oxidant species. This figure also includes other secondary oxidation mechanisms involving single-step reactions with $\mathrm{Cl}_{2}, \mathrm{O}_{3}, \mathrm{BrO}$, and $\mathrm{ClO}$ studies suggested that $\mathrm{Hg}(\mathrm{II})$ reduction could proceed via aqueous $\mathrm{SO}_{3}$ and $\mathrm{HO}_{2}$ reaction pathways ${ }^{16,17}$, but these pathways are now considered irrelevant at the global scale ${ }^{6}$. Therefore, the significance of atmospheric aqueous $\mathrm{Hg}$ (II) reduction and the validity of their inclusion in the global mercury CTMs has been questioned $6,17,18$.

None of the global mercury models has been used to test the possibility of an alternative explicit gas-phase photoreduction of $\mathrm{Hg}$ (II) compounds, due to the poor understanding of its mechanism and reaction rates $^{6}$. The most recent studies-albeit 27 years ago-suggested the absence of gas-phase photoreduction for $\mathrm{HgCl}_{2}$ and $\mathrm{Hg}(\mathrm{CN})_{2}$ and slow photoreduction rates ${ }^{19,20}$ for $\mathrm{Hg}(\mathrm{OH})_{2}$ and $\mathrm{Hg}(\mathrm{SH})_{2}$, despite an earlier study of the UV absorption cross sections which suggested that $\mathrm{HgBr}_{2}$ and $\mathrm{HgI}_{2}$ could undergo relatively fast photolysis ${ }^{21,22}$. As far as we are aware there have been no further experimental or theoretical studies on the photolytic properties of $\mathrm{Hg}(\mathrm{II})$ compounds of atmospheric relevance.

Here, we revisit the photoreduction pathways of atmospheric $\mathrm{Hg}(\mathrm{II})$ compounds. First, we show that irradiation experiments with boundary layer and free tropospheric rainwater do not support fast aqueous-phase $\mathrm{Hg}(\mathrm{II})$ photoreduction. We then compute the UV-VIS absorption cross sections of the following $\mathrm{Hg}(\mathrm{II})$ compounds: $\mathrm{HgCl}_{2}, \mathrm{HgBr}_{2}, \mathrm{HgBrOCl}, \mathrm{HgBrI}, \mathrm{HgBrOBr}$, $\mathrm{HgBrOI}, \mathrm{HgBrNO}_{2}, \mathrm{HgBrONO}, \mathrm{HgBrOH}, \mathrm{HgBrOOH}$, and $\mathrm{HgO}$, using high-level quantum chemical methods, and infer the corresponding atmospheric photoreduction rates. Our results show for the first time that gas-phase $\mathrm{Hg}(\mathrm{II})$ photoreduction can proceed at relevant timescales, and is more important than in-cloud $\mathrm{Hg}(\mathrm{II})$ photoreduction. The inclusion of this new gaseous-phase $\mathrm{Hg}(\mathrm{II})$ photoreduction mechanism in two state-ofthe-art global $\mathrm{Hg}$ models reveals major implications for our understanding of $\mathrm{Hg}$ cycling in the atmosphere, and its deposition to the surface environment.

\section{Results}

Laboratory rainfall $\mathrm{Hg}(\mathrm{II})$ photoreduction experiments. To study aqueous phase $\mathrm{Hg}$ (II) photoreduction, ten rainfall events were sampled in suburban Toulouse and at the high altitude (2877 m) Pic du Midi Observatory (PDM, France) in the summer of 2017. Rainfall samples were irradiated in a quartz reactor with natural sunlight or with a solar simulator (see Methods). We observe (Supplementary Figure 1a and 1b, Supplementary Data 1 and Supplementary Table 1) no statistically significant differences between rainfall $\mathrm{Hg}(\mathrm{II})$ reduction rates under natural $(0.063 \pm$ $\left.0.013 \mathrm{~h}^{-1}\right)$ and simulated sunlight $\left(0.037 \pm 0.016 \mathrm{~h}^{-1}\right)$, and for filtered $\left(0.058 \pm 0.011 \mathrm{~h}^{-1}\right)$ and unfiltered $\left(0.039 \pm 0.020 \mathrm{~h}^{-1}\right)$ suburban rainwater $(t$-test, all $p>0.05)$. The mean photochemical reduction rate of suburban rainfall was $0.051 \pm 0.019 \mathrm{~h}^{-1}(\sigma, n=$ $10)$. The mean rate at the remote PDM samples was two-fold higher, $0.15 \pm 0.01 \mathrm{~h}^{-1}(\sigma, n=3)$, than that of the suburban Toulouse samples, and three times slower than the median photoreduction rate of $0.41 \mathrm{~h}^{-1}(n=24)$ for inland and marine waters $^{15}$. Our experimental rainwater photoreduction rates, under fully sunlit conditions, are an order of magnitude slower than the optimized maximum in-cloud photoreduction rate $e^{6,23}$ of $>1.0 \mathrm{~h}^{-1}$ in global Hg CTMs.

Quantum chemical computation of gaseous $\mathrm{Hg}$ (II) absorption cross sections. We now turn to the computation of electronic spectra and absorption cross sections of gas-phase $\mathrm{Hg}$ (II) compounds which are required to estimate the corresponding photoreduction rates. A summary of the UV-VIS spectra and absorption cross sections, computed at the CASSCF/ MS-CASPT2/SO-RASSI level of theory (Methods), is presented 


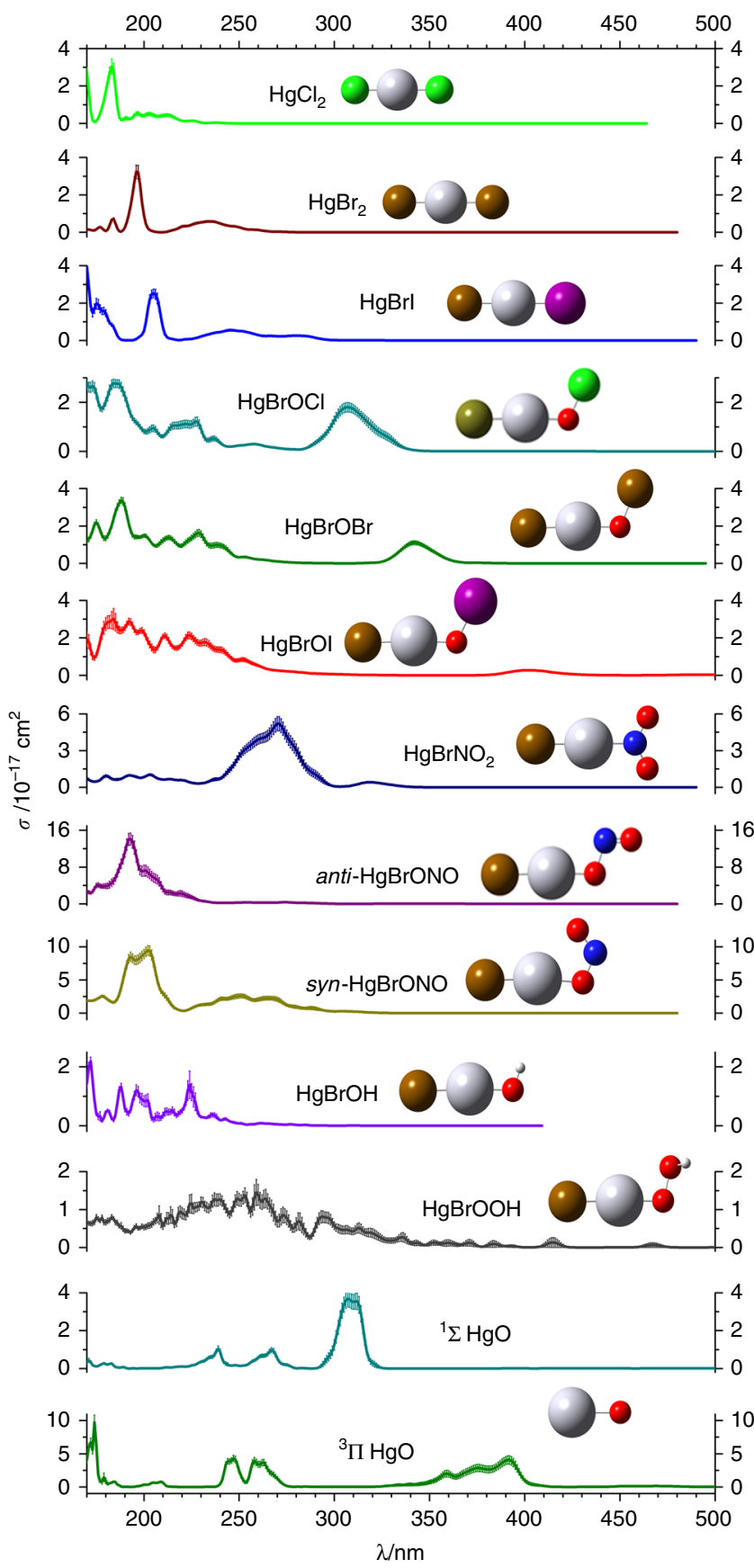

Fig. 2 Ball-and-stick representation and computed UV-VIS absorption spectra and cross sections $\left(\sigma, \mathrm{cm}^{2}\right)$ of the $\mathrm{Hg}(\mathrm{II})$ compounds studied in the present work. The light-coloured areas correspond to the uncertainty of the cross section due to the statistical sampling. Note the different range of $\sigma$ values for some of the spectra. Also note that only wavelengths $>290 \mathrm{~nm}$ are relevant for ambient tropospheric conditions

in Fig. 2 for the $170-600 \mathrm{~nm}$ wavelength range. The calculated spectra of $\mathrm{HgCl}_{2}$ and $\mathrm{HgBr}_{2}$ are in very good agreement with previous experimental ${ }^{22,24-26}$ and computed spectra ${ }^{21}$ (Fig. 3), thus providing strong support for the theoretical method applied here. The majority of the spectra consist of well-defined absorption bands in the $200-350 \mathrm{~nm}$ range, which are redshifted when $\mathrm{Cl}$ is replaced with $\mathrm{Br}$ and I atoms. Note that three different isomers could form from the reaction of $\mathrm{HgBr}$ with $\mathrm{NO}_{2}: \mathrm{HgBrNO}_{2}$, and syn- and anti-HgBrONO. However, high-

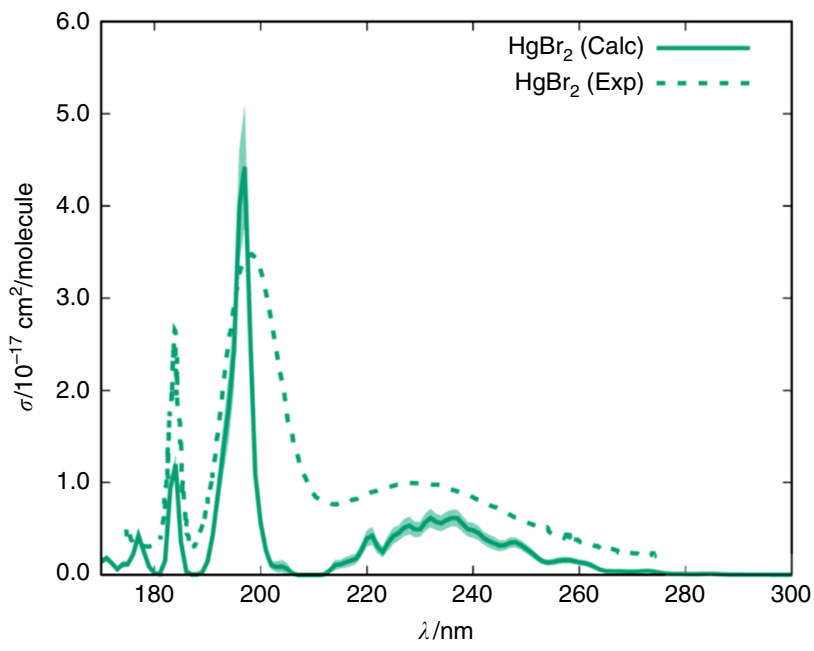

Fig. 3 Calculated and experimental cross section of gas-phase $\mathrm{HgBr}_{2}$. The calculated spectrum was obtained with the CASSCF/MS-CASPT2/SO RASSI methodological approach using the ANO-RCC-VTZP basis set. The light coloured areas correspond to the numerical error of absorption cross sections due to the statistical sampling

level quantum chemical computations ${ }^{27}$ indicate that syn$\mathrm{HgBrONO}$ is the most thermodynamically stable species.

Computation of photolysis rates and atmospheric lifetime of $\mathrm{Hg}$ (II) compounds. The annually averaged atmospheric lifetimes against photolysis in the troposphere for the $\mathrm{Hg}(\mathrm{II})$ compounds studied here are presented in Fig. 4 (see also Supplementary Table 2 and Supplementary Figure 2 for zonal-averaged atmospheric lifetimes). The species with the longest lifetime is $\mathrm{HgCl}_{2}$ (48 years), and the species with the shortest lifetime is $\mathrm{HgBrOBr}$ $(<1 \mathrm{~s})$. These lifetimes were calculated assuming a complete UVVIS photodissociation under atmospheric conditions. In the case of the parent $\mathrm{HgBr}_{2}$ compound, it is well known that irradiation with $\sim 200 \mathrm{~nm}$ UV light yields the monohalide $(\mathrm{HgBr})$ with nearly $100 \%$ efficiency ${ }^{25,28-30}$. Moreover, detailed quantumchemical computations of the $\mathrm{Cl}$ - and $\mathrm{Br}$-dihalides predict further efficient photodissociation at wavelength ${ }^{21}$ longer than 200 $\mathrm{nm}$. There are no comparable experimental or calculated photolysis data for the other $\mathrm{HgBr}-\mathrm{X}$ compounds studied here. Nevertheless, a similar very efficient photodissociation step is to be expected for these mercury halides considering the even lower dissociation energies of the $\mathrm{HgBr}-\mathrm{X}$ bond, as compared with that of the parent $\mathrm{HgBr}-\mathrm{Br}$ dihalide (Supplementary Table 3) ${ }^{9,27}$. In addition to this primary photolysis reaction to $\mathrm{HgBr}$, it has been shown that $\mathrm{Hg}(0)$ is also generated in the $\mathrm{HgBr}_{2}$ photodissociation through direct or secondary channels, although to a much lesser extent ${ }^{31,32}$. Based on this evidence, we consider in the atmospheric modelling below that $\mathrm{HgBr}$ is the main product of $\mathrm{HgBrX}$ photodissociation, although we also ran one scenario where $\mathrm{HgBrX}$ photodissociation results in $\mathrm{Hg}(0)$ production.

\section{Discussion}

The absorption cross sections of syn- $\mathrm{HgBrONO}, \mathrm{HgBrOOH}$, $\mathrm{HgBrOH}, \mathrm{HgBr}_{2}, \mathrm{HgBrOCl}$, and $\mathrm{HgBrOBr}$ were implemented into the GEOS-Chem ${ }^{6}$ and GLEMOS ${ }^{33,34}$ global $\mathrm{Hg}$ chemistry and transport models (Methods), since these $\mathrm{Hg}$ (II) species are the most likely to be formed in the atmosphere ${ }^{6,11,27}$. GEOSChem simulates $\mathrm{Hg}$ (II) as a single tracer, whereas GLEMOS simulates $\mathrm{Hg}$ (II) species individually. In GEOS-Chem the rapidly photolyzing $\mathrm{Hg}(\mathrm{II})$ species $(\mathrm{HgBr}-[\mathrm{ONO}, \mathrm{OOH}, \mathrm{OCl}, \mathrm{OBr}])$ are calculated to be at pseudo-steady-state with $\mathrm{HgBr}$. GLEMOS does 


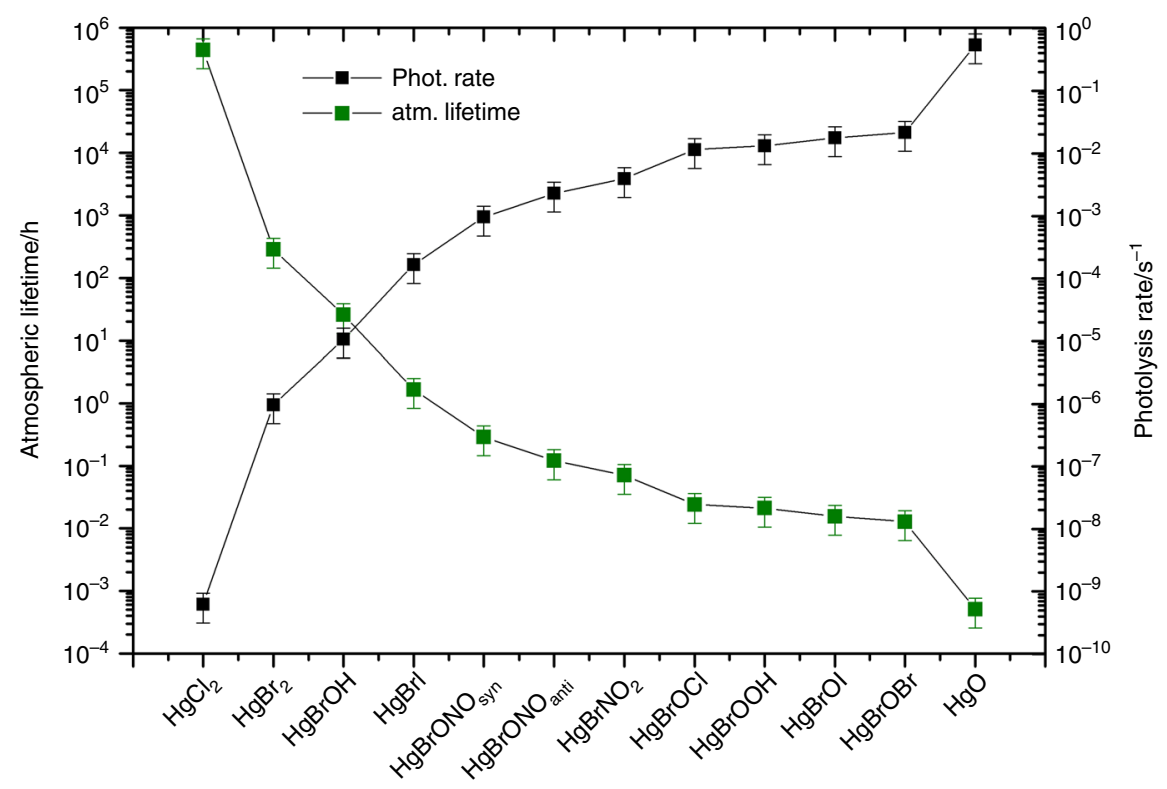

Fig. 4 Annually- and globally-averaged photolysis rate $\left(\mathrm{s}^{-1}\right)$ and lifetime (h) of $\mathrm{Hg}(\mathrm{II})$ compounds in the troposphere. Error bars correspond to one standard deviation

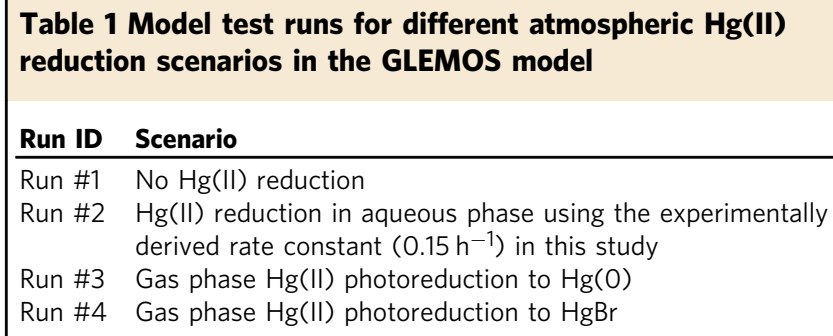

not include the highly uncertain reduction reaction ${ }^{6} \mathrm{HgBr}+$ $\mathrm{NO}_{2} \rightarrow \mathrm{Hg}(0)+\mathrm{BrNO}_{2}$. Omitting this reaction in GEOS-Chem lowers the $\mathrm{Hg}$ lifetime from 13 to 8 months in model Run\#4 (The different model simulated scenarios for atmospheric $\mathrm{Hg}(\mathrm{II})$ reduction are shown in Table 1). syn- $\mathrm{HgBrONO}$ and $\mathrm{HgBrOOH}$ generally dominate the production of $\mathrm{Hg}(\mathrm{II})$ in both models (Supplementary Figure 3), whilst $\mathrm{HgBr}_{2}$ becomes the prevalent $\mathrm{Hg}$ (II) species in the troposphere (Supplementary Figure 4) due to its longer lifetime against photolysis. Note that direct photoreduction to $\mathrm{Hg}(0)$ produces unrealistically long $\mathrm{Hg}$ lifetimes $>19$ months in both models. Therefore, photoreduction was considered to produce $\mathrm{HgBr}$ in all cases. Indeed, intensive photolysis of $s y n-\mathrm{HgBrONO}$ and $\mathrm{HgBrOOH}$ causes $\mathrm{HgBr}$ to be a relevant species in the free troposphere (Supplementary Figure 5 and Fig. 5). $\mathrm{HgBr}$ can then be re-oxidized to gaseous $\mathrm{Hg}(\mathrm{II})$, or decay to $\operatorname{Hg}(0)$ by thermal dissociation, which is strongly dependent on pressure and temperature ${ }^{6,9}$. Atmospheric aqueous $\mathrm{Hg}$ (II) reduction parameterizations in both models were capped with an upper limit that corresponds to our observed rainfall photoreduction rate constant, $k_{\mathrm{red}}=0.15\left(\mathrm{~h}^{-1}\right)$, leading to a $6 \%$ decrease in modelled atmospheric lifetime. Published model runs with capped aqueous phase $\mathrm{Hg}$ (II) reduction and without the gasphase photoreduction $6,33,34$ yield total atmospheric $\mathrm{Hg}$ lifetimes of 4.9 and 4.6 months against deposition. Our new results show that gaseous $\mathrm{Hg}(\mathrm{II})$ photoreduction increases the $\mathrm{Hg}$ lifetime to 13 and 10 months in GEOS-Chem and GLEMOS model Run\#4, respectively. We find that gas-phase photoreduction is the dominant reduction pathway.
We further examined the global atmospheric $\mathrm{Hg}(0)$ and $\mathrm{Hg}(\mathrm{II})$ distribution in GLEMOS. Figures 6 and 7 show the effect of the new photoreduction scheme on the global distribution of $\operatorname{Hg}(0)$ surface concentration. All these simulations were made with the previously assumed aqueous photoreduction mechanism removed. We find that simulations without the gaseous photoreduction lead to $35-40 \%$ underestimation of observed $\mathrm{Hg}(0)$ (Runs \#1 and \#2). The gas-phase $\mathrm{Hg}(\mathrm{II})$ photoreduction to $\mathrm{Hg}(0)$ (Run \#3) results in unrealistically high $\mathrm{Hg}(0)$ concentrations with almost two-fold overestimation of the observations and strong underestimation of wet deposition. The model run with the incorporation of the gas phase photoreduction to $\mathrm{HgBr}$ (Run \#4) shows that $\mathrm{Hg}(0)$ levels are $18 \%$ overestimated, and model $\mathrm{Hg}(\mathrm{II})$ wet deposition $20 \%$ underestimated with respect to observations (Fig. 7, Supplementary Table 4). The results of test Run\#4 are closest to the observations which suggest that gas-phase reduction processes are important but also that re-oxidation via the $\mathrm{HgBr}$ intermediate is important. An additional step in the evaluation of model results can be made by examining the variability of modelled and observed $\mathrm{Hg}$ concentrations. Previous studies indicated that longer $\mathrm{Hg}(0)$ lifetimes lead to lower simulated $\mathrm{Hg}$ $(0)$ variability, as represented by the standard deviation $(1 \sigma)$ of mean $\mathrm{Hg}(0)$ concentrations ${ }^{6,34}$. Here, gas-phase photoreduction leads to simulated $\mathrm{Hg}(0)$ levels at the measurement sites (1.62 \pm $0.36 \mathrm{ng} / \mathrm{m}^{3}, 1 \sigma$, STP) that have a larger standard deviation than observed $\operatorname{Hg}(0)\left(1.38 \pm 0.25 \mathrm{ng} / \mathrm{m}^{3}, 1 \sigma\right.$, STP $)$. This indicates that the longer $\mathrm{Hg}(0)$ lifetime estimates of 8-13 months resulting from model Run\#4 are broadly compatible with observed $\mathrm{Hg}(0)$ variability $(1 \sigma)$. The resulting global zonal distribution of $\mathrm{Hg}(0)$ and speciated $\mathrm{Hg}(\mathrm{II})$ (syn-HgBrONO$, \mathrm{HgBrOOH}, \mathrm{HgBrOH}$, $\mathrm{HgBr}, \mathrm{HgBr}_{2}$ ) reveals the major effects of gas-phase $\mathrm{Hg}(\mathrm{II})$ photoreduction in the global budget of atmospheric oxidized mercury (Supplementary Figures 4-9) and in the global patterns of mercury surface deposition (Fig. 8 and Supplementary Figure 10). In particular, it leads to a strong decrease of free tropospheric concentrations of syn- $\mathrm{HgBrONO}$ and $\mathrm{HgBrOOH}$, which were previously considered as dominant $\mathrm{Hg}$ (II) species. In contrast, concentrations of $\mathrm{HgBrOH}$ and $\mathrm{HgBr}_{2}$ increase due to the lower photolysis rates. The incorporation of gas-phase photoreduction leads to an increase in global $\mathrm{Hg}(0)$ deposition from 


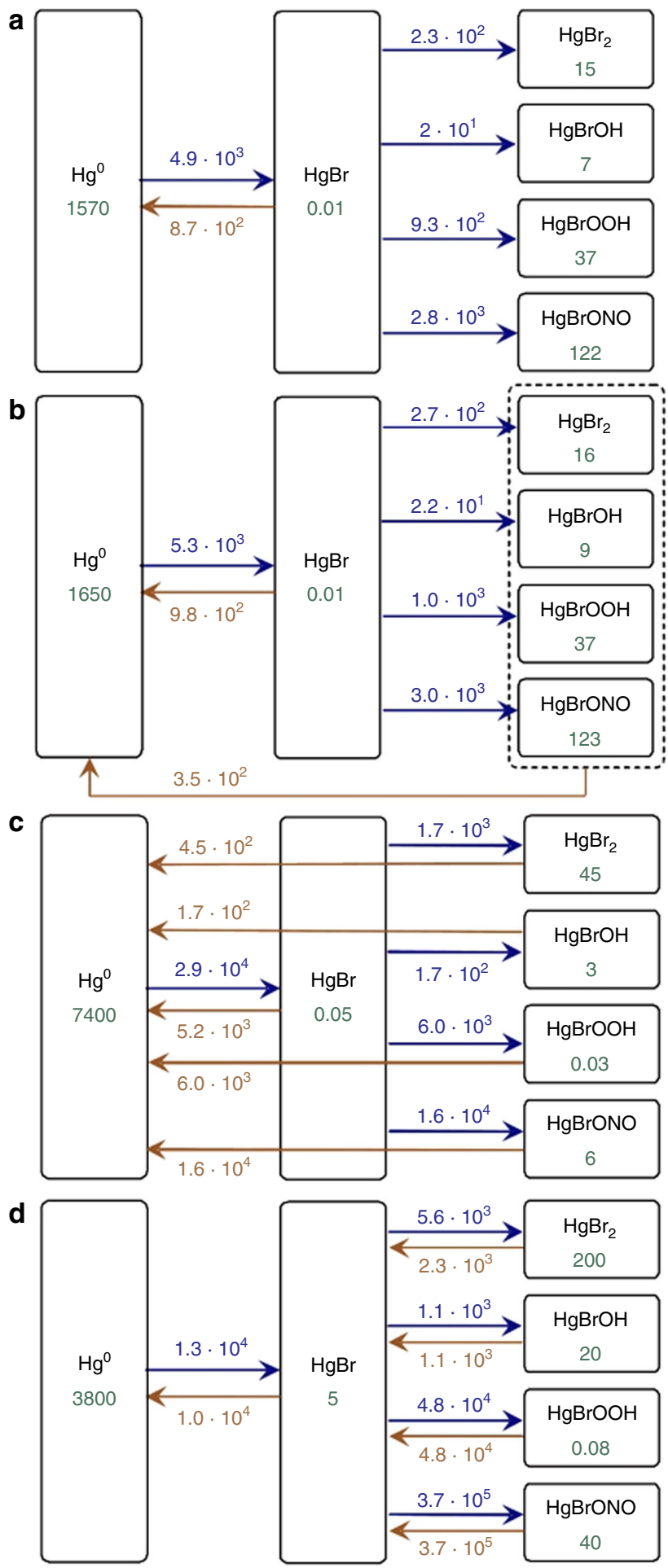

Fig. 5 Global budget of $\mathrm{Hg}$ chemical cycling covering the troposphere and lower stratosphere (up to ca. $30 \mathrm{kms}$ ) for different tests in GLEMOS: aRun \#1; b-Run \#2; c-Run \#3; d-Run \#4. The mass estimates are in $M g$, the fluxes are in $\mathrm{Mg} \mathrm{a}^{-1}$

$11 \%$ (Run\#1) to $24 \%$ (Run\#4) at the expense of $\mathrm{Hg}(\mathrm{II})$ deposition (down by 13\%, Fig. 8 and Supplementary Figure 10). We further observe a reduction of $\mathrm{Hg}$ deposition (dry and wet) to the ocean (down by 15\%, Fig. 8 and Supplementary Figure 10), and an increase of $\mathrm{Hg}(0)$ dry deposition to the land surface (22\%), particularly to vegetation in line with the recent findings that foliar uptake by vegetation drives continental $\mathrm{Hg}(0)$ seasonality ${ }^{7}$.
Global chemical budget diagrams (Fig. 5) summarize the $\mathrm{Hg}(0)$, $\mathrm{Hg}(\mathrm{I})$ and $\mathrm{Hg}(\mathrm{II})$ cycling in different model runs.

This work shows that the presence of an efficient gas-phase $\mathrm{Hg}$ (II) photoreduction challenges the current understanding of $\mathrm{Hg}$ cycling in the atmosphere and its deposition to the surface environment. We show that the new gas-phase $\mathrm{Hg}$ (II) photoreduction mechanism is likely the dominant reduction pathway for atmospheric mercury which can change the concept of the speciation of $\mathrm{Hg}(\mathrm{II})$ in the atmosphere. Its inclusion in state-ofthe-art global models leads to significant modifications in the local scale deposition of $\mathrm{Hg}$ to the Earth's surface. As a result, enhanced deposition to land surfaces may prolong recovery of aquatic ecosystems long after $\mathrm{Hg}$ emissions are curbed, due to the longer residence time of $\mathrm{Hg}$ in soils than in ocean $\mathrm{s}^{35}$.

\section{Methods}

Computation of UV-Vis absorption spectra and cross sections. A theoretical methodology previously calibrated ${ }^{36}$ was used for calculating the electronic absorption spectra and cross-sections of $\mathrm{HgCl}_{2}, \mathrm{HgBr}_{2}, \mathrm{HgBrI}, \mathrm{HgBrOBr}, \mathrm{HgBrOI}$, $\mathrm{HgBrOCl}, \mathrm{HgBrNO}_{2}, \mathrm{HgBrONO}, \mathrm{HgBrOH}, \mathrm{HgBrOOH}$, and $\mathrm{HgO}$ (The absorption cross sections are reported in Supplementary Data 2). Specifically, vertical transitions energies from the ground to electronically excited states and the corresponding oscillator strengths were computed with the highly accurate multireference complete-active-space self-consistent field/multistate completeactive-space second-order perturbation theory (CASSCF/MS-CASPT2) $\operatorname{method}^{37}$ and the atomic-natural-orbital relativistic correlation-consistent valence triple- $\zeta$ plus polarization (the ANO-RCC-VTZP) basis set ${ }^{38}$, taking into account scalar relativistic and spin-orbit coupling (SOC) effects (see below and Supplementary Table 5 for further details). Scalar relativistic effects were included by means of the third-order Douglas-Kroll and Hess (DKH3) Hamiltonian, and the spin-orbit coupling (SOC) was computed using the restricted active space state interaction (RASSI) method, as implemented in the MOLCAS 8 program $^{39}$.

The atmospheric modelling methods used in the present work require as input data the absorption cross sections of any compound that may undergo photolysis in the UV-VIS range under atmospheric conditions. To estimate the vibrational resolution and determine the band shapes, absorption spectra were generated for all the compounds studied here by sampling the nuclear coordinates of the groundstate equilibrium structure and frequencies according to a Wigner distribution, as described in refs 40,41 and subsequently computing the vertical transition energies and oscillator strengths at each structure. The Wigner distribution of geometries was obtained with the Newton-X 1.4 program ${ }^{42,43}$, and an in-house program was used to compute the cross sections from the energies and oscillator strengths generated by the MOLCAS program. The ground-state structures and frequencies needed to generate the Wigner distribution were obtained by using the PBE0 functional $^{44}$ with the Def2QZVP basis set ${ }^{45-47}$ as implemented in the Gaussian 09 package ${ }^{48}$. The minor differences observed in the simulated spectra due to groundstate geometries generated using either CASPT2, CCSD, or DFT methods are presented in Supplementary Figure 11.

For the di- and triatomic systems, appropriate symmetry point groups available in the MOLCAS program and which enabled for every possible displacement of atoms, were used in the calculations- $\mathrm{C}_{2 \mathrm{v}}$ in $\mathrm{HgO}$ and $\mathrm{C}_{\mathrm{s}}$ in $\mathrm{HgCl}_{2}, \mathrm{HgBr}_{2}$, and $\mathrm{HgBrI}$. For other studied systems, no symmetry was adopted $\left(\mathrm{C}_{1}\right.$ group). For each particular system, the number of spin-free states to account for in the CASSCF/MSCASPT2 calculations were selected according to the energy criteria in such way to include all relevant electronic transitions up to $170 \mathrm{~nm}$ (and later apply SOC effects). All the parameters of the carried simulations of the spectra, such as the number of sampled geometries $\mathrm{N}_{\mathrm{p}}$, broadening of the Gaussian shape functions $\delta$, and the numbers of included states per symmetry, are presented in detail in Supplementary Table 5.

By using the Wigner distribution of geometries for estimating the vibrational structure of the spectra and the CASSCF/MS-CASPT2/SO-RASSI methodology for determining the electronic structure, the agreement between computed and experimental transition energies was in the range of 5-10\%, for those few cases in which gas-phase experimental data were available, namely for mercury compounds $\mathrm{HgCl}_{2}$ and $\mathrm{HgBr}_{2}$ (Fig. 3). The corresponding uncertainty in the calculated crosssection values is $\pm 25 \%$ for the most intense transitions (see Fig. 3 ), similar to the actual dispersion of the experimental values $22,24-26$

The selected active spaces for the CASSCF/MS-CASPT2 computations are briefly discussed here. First general details are given and next we discuss those aspects which refer to each group of compounds.

According to our previous work on benchmarking the methodology for the representative $\mathrm{HgBr}_{2}$ molecule ${ }^{36}$ and on the basis of several test CASSCF computations with distinct active spaces for the whole set of molecules, some rules regarding the selection of the active spaces could be established.

First, for all the systems, s-subshell orbitals (and electrons) are not relevant in the studied energy range (up to $170 \mathrm{~nm}$ ) and therefore were kept inactive and 

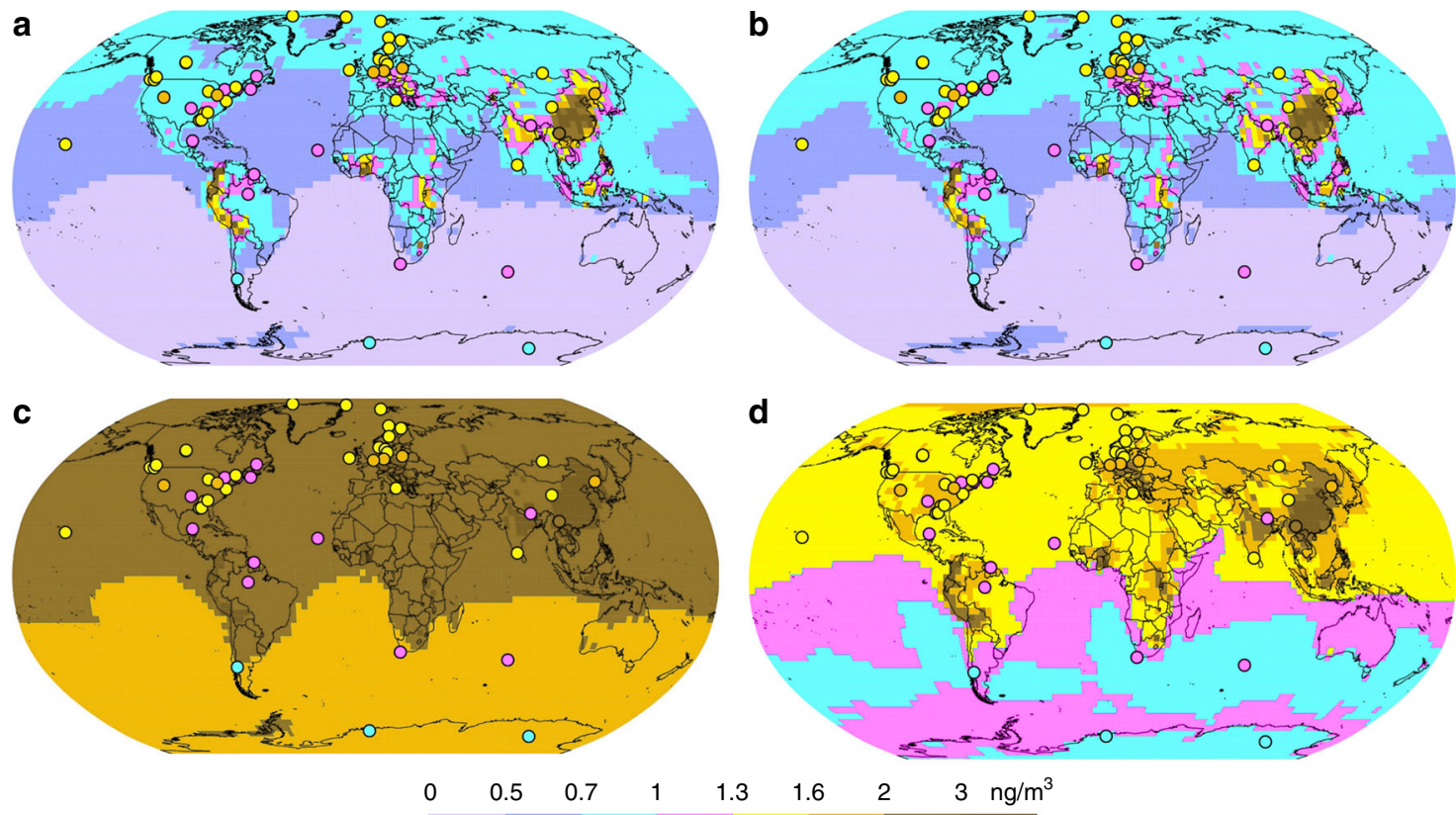

Fig. 6 Spatial distribution of $\mathrm{Hg}(0)$ surface concentration for different atmospheric $\mathrm{Hg}(\mathrm{II})$ reduction simulations in the GLEMOS model: a Run \#1; b Run \#2; c Run \#3; d Run \#4. Circles show observed values in the same colour scale. The measurement dataset is the same as in ref. 35
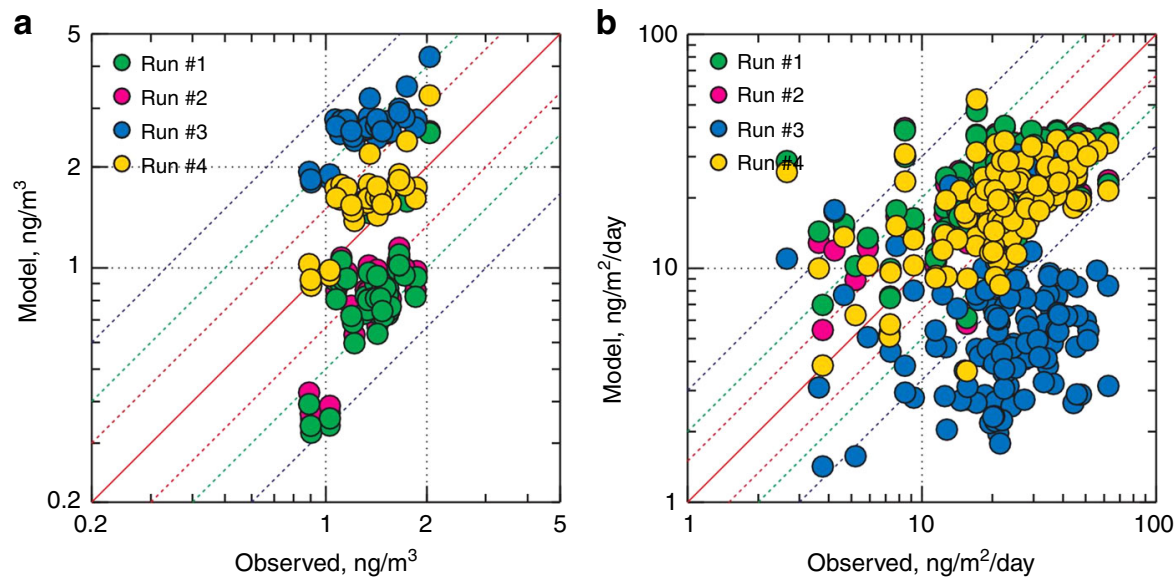

Fig. 7 Comparison between simulations from the GLEMOS model with measurements for the year 2013: a $\mathrm{Hg}(0)$ air concentration; b Hg(II) wet deposition. The measurement dataset is the same as in ref. 35

doubly occupied, except for the 6s orbital of $\mathrm{Hg}$, which has a key role in the transitions.

Second, the $5 \mathrm{~d}$ orbitals of $\mathrm{Hg}$ are not involved in the transitions within the energy region of our interest, and therefore were not correlated in the CASSCF/ MS-CASPT2 simulations for any system with the exception of the $1^{1} \Sigma$ and $1^{3} \Pi$ states of $\mathrm{HgO}$. For this system, tests showed a small contribution of the $5 \mathrm{~d}$ orbitals for high-energy transitions close to $170 \mathrm{~nm}$.

Third, the $6 \mathrm{p}$ orbitals of $\mathrm{Hg}$, especially those perpendicular to $\sigma$ orbitals of $\mathrm{Hg}$ $\mathrm{X}$, namely $6 \mathrm{p}_{\mathrm{x}}$ and $6 \mathrm{p}_{\mathrm{y}}$, should be correlated at the CASSCF level. On the other hand, test calculations have shown that the $\mathrm{Hg}$ atomic orbital of $6 \mathrm{p}_{\mathrm{z}}$-type, colinear with mercury covalent bonds, has no weight in the transitions relevant for this study, and was not included in the active spaces for the larger-size systems.

Finally, the two last natural orbitals (NOs) of non-bonding character, consisting on $\mathrm{Br} 4 \mathrm{~d}_{\mathrm{xz} / \mathrm{yz}}+\mathrm{Br} 4 \mathrm{~d}_{\mathrm{xz} / \mathrm{yz}}$ atomic orbitals (AOs) and used in our first benchmark study on $\mathrm{HgBr}_{2}{ }^{36}$, were not necessary for the computations and were omitted in the di- and triatomic systems, in order to reduce computational effort.

For each particular compound, the following criteria were adopted

For $\mathrm{HgCl}_{2} \mathrm{HgBr}_{2}$ and $\mathrm{HgBrI}$, the optimal active spaces consisted of 12 electrons distributed in 10 NOs of the following character: $\sigma / \sigma^{*}$-type $\left(\mathrm{Hg} 6 \mathrm{~s} \pm \mathrm{Cl} 3 \mathrm{p}_{\mathrm{z}} / \mathrm{Br} 4 \mathrm{p}_{\mathrm{z}} /\right.$ I $5 \mathrm{p}_{\mathrm{z}}$ and $\left.\mathrm{Hg} 6 \mathrm{p}_{\mathrm{z}} \pm \mathrm{Cl} 3 \mathrm{p}_{\mathrm{z}} / \mathrm{Br} 4 \mathrm{p}_{\mathrm{z}} / \mathrm{I} 5 \mathrm{p}_{\mathrm{z}}\right), \sigma^{\text {nb }}$-type $\left(\mathrm{Cl} 3 \mathrm{p}_{\mathrm{z}} / \mathrm{Br} 4 \mathrm{p}_{\mathrm{z}} / \mathrm{I} 5 \mathrm{p}_{\mathrm{z}}\right)$, and $\pi^{\mathrm{nb}}$ type $\left(\mathrm{Cl} 3 \mathrm{p}_{\mathrm{x} / \mathrm{y}} / \mathrm{Br} 4 \mathrm{p}_{\mathrm{x} / \mathrm{y}} / \mathrm{I} 5 \mathrm{p}_{\mathrm{x} / \mathrm{y}}\right.$ and $\left.\mathrm{Hg} 6 \mathrm{p}_{\mathrm{x} / \mathrm{y}}\right)$. Although included in the active space, the $\sigma^{*}$ orbital, $\mathrm{Hg} 6 \mathrm{p}_{\mathrm{z}} \pm \mathrm{Cl} 3 \mathrm{p}_{\mathrm{z}} / \mathrm{Br} 4 \mathrm{p}_{\mathrm{z}} /$ I $5 \mathrm{p}_{\mathrm{z}}$ was not significantly occupied in the electronic configurations.
For ${ }^{1} \Sigma \mathrm{HgO}$ and ${ }^{3} \Pi \mathrm{HgO}$ the optimal active spaces consisted of 16 electrons distributed in 12 NOs. For these systems only, the active space additionally had to include 10 electrons belonging to the $\mathrm{Hg} 5 \mathrm{~d}$-subshell, and the remaining NOs were of the following type: $\sigma / \sigma^{*}$-type ( $\mathrm{Hg} 6 \mathrm{~s} \pm \mathrm{O} 2 \mathrm{p}_{\mathrm{z}}$ and $\mathrm{Hg} 6 \mathrm{p}_{\mathrm{z}} \pm \mathrm{O} 2 \mathrm{p}_{\mathrm{z}}$ ), and $\pi^{\mathrm{nb}}$-type $\left(\mathrm{O} 2 \mathrm{p}_{\mathrm{x} / \mathrm{y}}\right.$ and $\left.\mathrm{Hg} 6 \mathrm{p}_{\mathrm{x} / \mathrm{y}}\right)$. In contrast to the other systems studied, $\sigma^{*} \mathrm{Hg} 6 \mathrm{p}_{\mathrm{z}}+\mathrm{O} 2 \mathrm{p}_{\mathrm{z}}$ had an observable contribution in the configuration characterizing the excited states.

For $\mathrm{HgBrOBr}$ and $\mathrm{HgBrOI}$ the optimal active spaces consisted of 16 electrons distributed over 12 NOs. They correspond to the NOs formed by Hg $6 \mathrm{~s}$ and AOs of p-type: $\mathrm{O} 2 \mathrm{p}_{\mathrm{x} / \mathrm{y} / \mathrm{z}}, \mathrm{Br} 4 \mathrm{p}_{\mathrm{x} / \mathrm{y} / \mathrm{z}} / \mathrm{I} 5 \mathrm{p}_{\mathrm{x} / \mathrm{y} / \mathrm{z}}$ and $\mathrm{Hg} 6 \mathrm{p}_{\mathrm{x} / \mathrm{y}}$. Tests have shown that for the energy region of interest in the UV-VIS range, there are no relevant transitions to the $\mathrm{Hg} 6 \mathrm{p}_{\mathrm{z}}$ orbital, and therefore it was not included in the active space to speed up the calculations.

For syn- $\mathrm{HgBrONO}$ and anti- $\mathrm{HgBrONO}$ and $\mathrm{HgBrNO}_{2}$. isomers, the optimal active spaces consisted of 16 electrons distributed in 12 NOs. They correspond to NOs formed by $\mathrm{Hg} 6 \mathrm{~s}$ and the AOs of p-type: $\mathrm{O} 2 \mathrm{p}_{\mathrm{x} / \mathrm{y} / \mathrm{z}}, \mathrm{Br} 4 \mathrm{p}_{\mathrm{x} /}$ $\mathrm{y} /$ and $\mathrm{Hg} 6 \mathrm{p}_{\mathrm{x} / \mathrm{y}}$. Some orbitals from the valence space of the ONO and $\mathrm{NO}_{2}$ groups had to be omitted due to the computational limitations. Tests have shown that for the relevant wavelength region in the UV-VIS, one $\sigma$-type bonding $\mathrm{NO}$ at the $\mathrm{O}-\mathrm{N}-\mathrm{O}$ and $\mathrm{NO}_{2}$ groups of atoms remains doubly occupied and it was moved to the inactive space, whereas the $\mathrm{Hg} 6 \mathrm{p}_{\mathrm{z}}$ orbital and higher $\sigma^{*}$-type virtual orbitals do not contribute significantly and therefore were kept in the secondary space. 

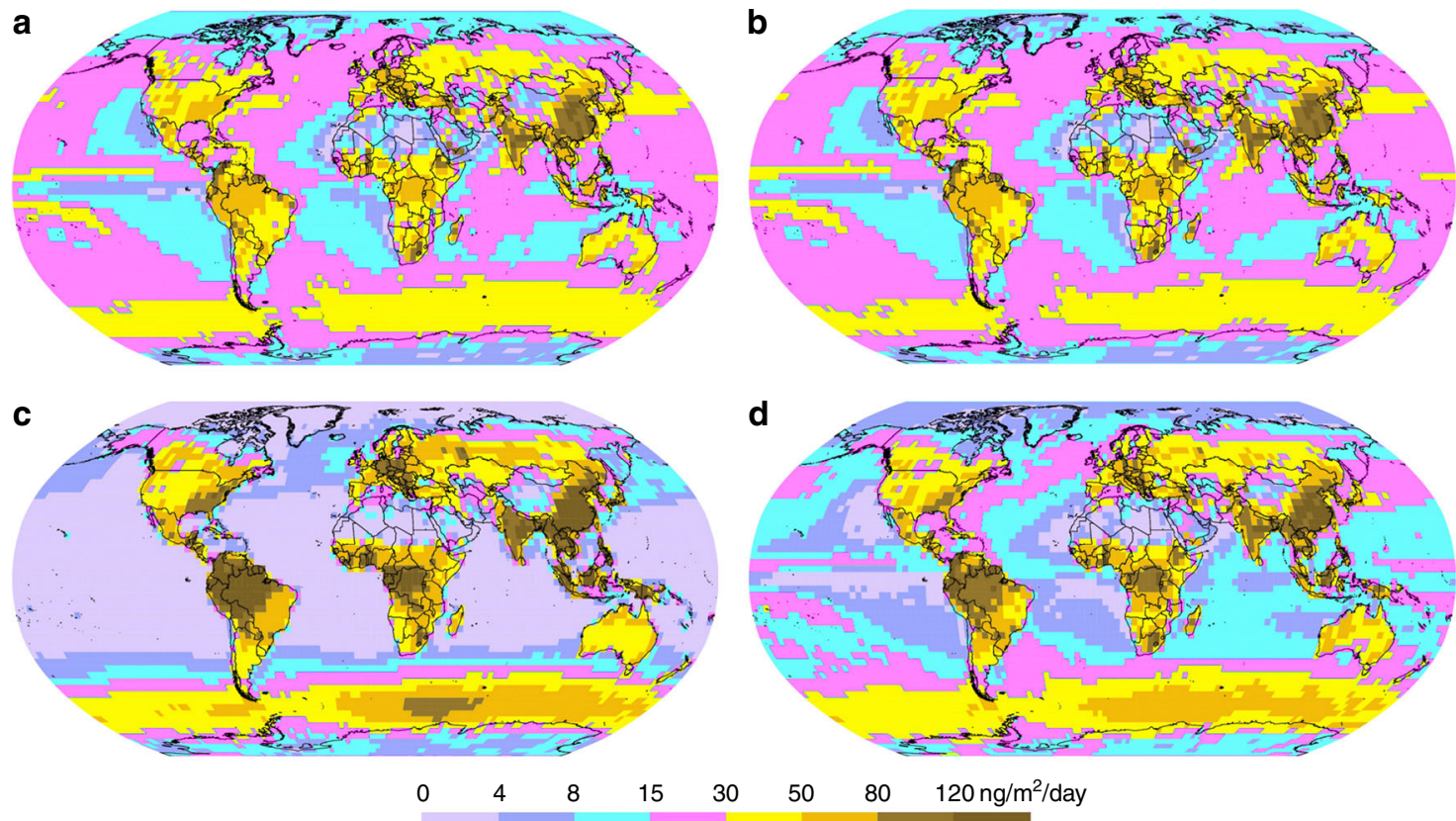

Fig. 8 Spatial distribution of total $\mathrm{Hg}$ (i.e. $\mathrm{Hg}(0)+\mathrm{Hg}(\mathrm{II})$ ) deposition for different tests in GLEMOS: a-Run \#1; b-Run \#2; c-Run \#3; d-Run \#4

In the case of $\mathrm{HgBrOOH}$, the optimal active space was similar to those of $\mathrm{HgBrOBr}$ and $\mathrm{HgBrOI}$. It consisted of 16 electrons distributed in $12 \mathrm{NOs}$ formed by $\mathrm{Hg} 6 \mathrm{~s}$ and $\mathrm{AOs}$ of $\mathrm{p}$-type: $\mathrm{O} 2 \mathrm{p}_{\mathrm{x} / \mathrm{y} / \mathrm{z}}, \mathrm{Br} 4 \mathrm{p}_{\mathrm{x} / \mathrm{y} / \mathrm{and}} \mathrm{Hg} 6 \mathrm{p}_{\mathrm{x} / \mathrm{y}}$. As for in previous cases, the $\mathrm{Hg} 6 \mathrm{p}_{\mathrm{z}}$ orbital was kept inactive since it was not relevant. In the case of $\mathrm{HgBrOH}$, the appropriate active space was 12 electron distributed in $11 \mathrm{NOs}$.

To test the effect of the geometries used in the Wigner distribution on the simulated UV-VIS spectra, the optimization of the geometry of the ground state and the frequencies of normal modes were obtained using three different quantumchemical methods for the representative $\mathrm{HgBr}_{2}$ molecule:

- DFT/PBE0/Def2QZVP

- $\mathrm{CCSD} / \mathrm{Def} 2 \mathrm{QZVP}$, and

- SS-CASPT2(12,10)/ANO-RCC-VTZP

Next, the computations of the electronic structure of the excited states were done for each set of geometries at the same level of theory: SOC-DKH3-MSCASPT2(12,10)/ANO-RCC-VTZP. The same number of sampled geometries $N_{\mathrm{p}}$ and broadening of the Gaussian shape functions $\delta$, were also chosen for the three sets of calculations: $N_{\mathrm{p}}=100$ and $\delta=0.05 \mathrm{eV}$, as shown in Supplementary Table 5 .

The UV-VIS absorption spectra obtained when using the differently generated sets of geometries is presented in Supplementary Figure 11 for $\mathrm{HgBr}_{2}$. As can be seen, no significant differences are obtained, which validates the use of the less computationally costly method (DFT) for the simulations in the other molecules.

Computation of the photolysis rates. In this study we employ the global 3D chemistry-climate model CAM-Chem (Community Atmospheric Model with chemistry, version 4.0), to estimate the photolysis rate $(J)$, and therefore the atmospheric lifetime $(\tau=1 / J)$, of the different $\mathrm{Hg}$ (II) species according to their computed absorption cross section. The model includes a comprehensive chemistry scheme to simulate the evolution of trace gases and aerosols in the troposphere and the stratosphere ${ }^{49}$. The model runs with the chlorine, iodine and bromine chemistry schemes from previous studies ${ }^{50-52}$, including the photochemical breakdown of bromo- and iodo-carbons emitted from the oceans ${ }^{49}$ and abiotic oceanic sources ${ }^{53}$ of $\mathrm{HOI}$ and $\mathrm{I}_{2}$. We have included all the $\mathrm{Hg}(\mathrm{II})$ species ( $\mathrm{HgCl}_{2}, \mathrm{HgBr}_{2}, \mathrm{HgBrI}, \mathrm{HgBrOCl}, \mathrm{HgBrOBr}, \mathrm{HgBrOI}, \mathrm{HgBrNO}_{2}, \mathrm{HgBrONO}$ (syn and anti), $\mathrm{HgBrOH}, \mathrm{HgBrOOH}$, and $\mathrm{HgO}$ ) and their computed absorption cross sections. CAM-Chem has been configured in this work with a horizontal resolution of $1.9^{\circ}$ latitude by $2.5^{\circ}$ longitude and 26 vertical levels, from the surface to $\sim 40 \mathrm{~km}$ altitude. The model run in this study was performed in the specified dynamics mode ${ }^{49}$ using offline meteorological fields instead of an online calculation. This offline meteorology consists of a high-frequency meteorological input from a previous free running climatic simulation ${ }^{54}$.

Description of the GEOS-Chem model. In this study, we use the GEOS-Chem $\mathrm{Hg}$ simulation from ref. ${ }^{6}$ using the surface slab ocean boundary parametrization ${ }^{55}$. The model calculates the transport and chemistry of tracer species $\mathrm{Hg}(0)$ and $\mathrm{Hg}$ (II). The parametrization of gas-particle partitioning of $\mathrm{Hg}(\mathrm{II})$ is from ref. ${ }^{56}$, and the mercury redox chemistry (described in detail in Supplementary Table 6) includes $\mathrm{Br}$ - and $\mathrm{Cl}$-initiated oxidation. Radical concentrations for $\mathrm{Hg}$ redox chemistry are from ref. ${ }^{57}$ with a diurnal cycle based on solar zenith angle imposed on top of monthly averages. Photolysis of $\mathrm{HgBr}-\mathrm{X}$ species is calculated using the GEOS-Chem implementation ${ }^{58}$ of the Fast-JX code ${ }^{59}$.

Description of the GLEMOS model. For evaluation of the new $\mathrm{Hg}$ chemical mechanisms under the atmospheric conditions we apply the 3D multi-scale chemical transport model GLEMOS (Global EMEP Multi-media Modelling System). The model simulates atmospheric transport, chemical transformations and deposition of $\mathrm{Hg}$ species $33,34,60$. In this study the model grid has a horizontal resolution $3^{\circ} \times 3^{\circ}$ and covers troposphere and lower stratosphere up to $10 \mathrm{hPa}$ (ca. $30 \mathrm{~km}$ ) with 20 irregular terrain-following sigma layers. The atmospheric transport of the tracers is driven by meteorological fields generated by the Weather Research and Forecast modelling system (WRF) ${ }^{61}$ fed by the operational analysis data from the European Centre for Medium-Range Weather Forecasts (ECMWF) (ECMWF, $2018)^{62}$. In the current version the model transports $\mathrm{Hg}(0)$ and four $\mathrm{Hg}$ (II) species $\left(\mathrm{HgBr}_{2}, \mathrm{HgBrOH}, \mathrm{HgBrOOH}, \mathrm{HgBrNO}_{2}\right)$ as separate species. Gas-particle partitioning of $\mathrm{Hg}$ (II) is parameterized following ref. ${ }^{56}$. A two-step mechanism of $\mathrm{Hg}$ (0) oxidation by $\mathrm{Br}$ in gas phase is included (ref. ${ }^{63}$ ):

$$
\begin{gathered}
\mathrm{Hg}(0)+\mathrm{X}+\mathrm{M} \rightarrow \mathrm{Hg}^{\mathrm{I}} \mathrm{X}+\mathrm{M} \\
\mathrm{Hg}^{\mathrm{I}} \mathrm{X}+\mathrm{M} \rightarrow \mathrm{Hg}(0)+\mathrm{X}+\mathrm{M} \\
\mathrm{Hg}^{\mathrm{I}} \mathrm{X}+\mathrm{Y} \rightarrow \mathrm{Hg}(0)+\mathrm{XY} \\
\mathrm{Hg}^{\mathrm{I}} \mathrm{X}+\mathrm{Y}+\mathrm{M} \rightarrow \mathrm{Hg}(\mathrm{II}) \mathrm{XY}+\mathrm{M},
\end{gathered}
$$

The full reaction scheme is listed in Supplementary Table 6. Briefly, $\mathrm{X} \equiv \mathrm{Br}$ is the first-step $\operatorname{Hg}(0)$ oxidant, $Y$ is the second-step $\mathrm{Hg}(\mathrm{I})$ oxidant, and $\mathrm{M}$ is a molecule of air. The reaction rate constants are from: ref. ${ }^{64}$ for R1; ref. ${ }^{9}$ for R2; ref. ${ }^{63}$ for $\mathrm{Y} \equiv \mathrm{Br}$ in $\mathrm{R} 3$; ref. ${ }^{12}$ for $\mathrm{Y} \equiv \mathrm{Br}$ and $\mathrm{OH}$ in $\mathrm{R} 4$; ref. ${ }^{27}$ for $\mathrm{Y} \equiv \mathrm{HO}_{2}$ and $\mathrm{NO}_{2}$ in R4. Six-hourly concentration fields of $\mathrm{Br}$ are archived from a GEOS-Chem simulation ${ }^{65}$, whereas $\mathrm{OH}, \mathrm{HO}_{2}, \mathrm{NO}_{2}$, and particulate matter $\left(\mathrm{PM}_{2.5}\right)$ fields are imported from MOZART ${ }^{66}$. The aqueous-phase chemistry includes oxidation ${ }^{10,67,68}$ of $\mathrm{Hg}(0)$ by dissolved $\mathrm{O}_{3}, \mathrm{OH}$ and $\mathrm{Cl}(\mathrm{I})^{\mathrm{I}}$. We have included the gas-phase photoreduction of $\mathrm{HgBr}_{2}, \mathrm{HgBrOH}, \mathrm{HgBrOOH}$, syn- $\mathrm{HgBrONO}$ using the rates calculated by CAM-Chem and the aqueous-phase photoreduction in cloud droplets with the photolysis rate constant $0.15 \mathrm{~h}^{-1}$ estimated in this study. We perform simulations for the period 2007-2013 using anthropogenic emissions for 2010 (AMAP/UNEP, 2013) ${ }^{69}$. Prescribed fluxes of $\mathrm{Hg}$ natural and secondary emissions from soil and seawater are generated depending on $\mathrm{Hg}$ concentration in soil, soil temperature and solar radiation for emissions from land and proportional 
to the primary production of organic carbon in seawater for emissions from the ocean $^{60}$. The first 6 years of the period are used for the model spin up to achieve the steady-state $\mathrm{Hg}$ concentrations in the troposphere. The model results are presented as annual averages for 2013 .

Description of rainfall $\mathbf{H g}$ (II) gross reduction rate experiments. Ten rainfall events were sampled in suburban Toulouse and at the high mountaintop Pic du Midi Observatory (France) in the summer of 2017 using ultra-clean methods ${ }^{70}$. Rainfall samples were transferred to a $0.5 \mathrm{~L}$ quartz reactor and illuminated with natural sunlight outdoors (up to $8 \mathrm{~h}$ ), or with a solar simulator indoors (up to 48 h). Filtered samples were passed through a 0.45 micro-m quartz filter membrane to remove particles, in unfiltered samples this step was left out. Total Hg concentration of selected rainfall samples was augmented $10 \times$ with a NIST 3133 standard $\mathrm{Hg}$ solution, and equilibrated $24 \mathrm{~h}$ before light exposure. During light exposure, the quartz reactor was purged with $\mathrm{Hg}$-free argon gas to remove product $\mathrm{Hg}(0)$. Reactant $\mathrm{Hg}(\mathrm{II})$ concentrations were measured in duplicate by cold vapour atomic fluorescence spectroscopy (CV-AFS) in $5 \mathrm{~mL}$ aliquots recovered from the reactor at fixed time steps and acidified to $0.04 \mathrm{M} \mathrm{HCl}$, and $0.1 \mathrm{M} \mathrm{BrCl}$. CV-AFS analysis accuracy was evaluated by regular analysis of the NRC ORMS- 6 certified $\left(25.6 \mathrm{ng} \mathrm{L}^{-1}\right)$ reference material with good results $\left(24.8 \pm 1.6 \mathrm{ng} \mathrm{L}^{-1}, 1 \sigma\right.$, $n=33$ ). Five out of twelve experiments showed increasing or constant reactant $\mathrm{Hg}$ (II) levels during the initial 2-4 hours, followed by a gradual decreasing in the final $24 \mathrm{~h}$ (Supplementary Data 1 ). These initial observations, tentatively explained by $\mathrm{Hg}$ (II)-DOM interaction with the quartz reactor wall, were not included in the rate constant calculation. This simplification did not affect the main outcome of this study. For further discussion on in-cloud Hg photoreduction see Supplementary Note.

Code availability. The code used in this study is available upon request.

\section{Data availability}

The data that supports the findings of this study is available upon request.

Received: 29 June 2018 Accepted: 11 October 2018

Published online: 15 November 2018

\section{References}

1. Streets, D. G. et al. Total mercury released to the environment by human activities. Environ. Sci. Technol. 51, 5969-5977 (2017).

2. Pacyna, E. G. et al. Global emission of mercury to the atmosphere from anthropogenic sources in 2005 and projections to 2020. Atmos. Environ. 44, 2487-2499 (2010).

3. Deeds, D. A. et al. Development of a particle-trap preconcentration-soft ionization mass spectrometric technique for the quantification of mercury halides in air. Anal. Chem. 87, 5109-5116 (2015).

4. Ernest, C. T., Donohoue, D., Bauer, D., Schure, A. T. \& Hynes, A. J. Programmable thermal dissociation of reactive gaseous mercury, a potential approach to chemical speciation: Results from a field study. Atmosphere $\mathbf{5}$, 575-596 (2014).

5. Ariya, P. A. et al. Mercury physicochemical and biogeochemical transformation in the atmosphere and at atmospheric interfaces: a review and future directions. Chem. Rev. 115, 3760-3802 (2015).

6. Horowitz, H. M. et al. A new mechanism for atmospheric mercury redox chemistry: Implications for the global mercury budget. Atmos. Chem. Phys. 17, 6353-6371 (2017).

7. Jiskra, M. et al. A vegetation control on seasonal variations in global atmospheric mercury concentrations. Nat. Geosci. 11, 244-250 (2018).

8. Global Mercury Assessment 2013: Sources, Emissions, Releases and Environmental Transport, UNEP: UNEP Chemicals Branch, Geneva, Switzerland, 2013.

9. Dibble, T. S., Zelie, M. J. \& Mao, H. Thermodynamics of reactions of $\mathrm{ClHg}$ and $\mathrm{BrHg}$ radicals with atmospherically abundant free radicals. Atmos. Chem. Phys. 12, 10271-10279 (2012).

10. Lin, C.-J. \& Pehkonen, S. O. The chemistry of atmospheric mercury: a review. Atmos. Environ. 33, 2067-2079 (1999).

11. Wang, F. et al. Enhanced production of oxidised mercury over the tropical Pacific Ocean: a key missing oxidation pathway. Atmos. Chem. Phys. 14, 1323-1335 (2014).

12. Goodsite, M. E., Plane, J. \& Skov, H. A theoretical study of the oxidation of $\mathrm{Hg} 0$ to $\mathrm{HgBr}_{2}$ in the troposphere. Environ. Sci. Technol. 38, 1772-1776 (2004).

13. Holmes, C. D., Jacob, D. J. \& Yang, X. Global lifetime of elemental mercury against oxidation by atomic bromine in the free troposphere,. Geophys. Res. Lett. 33, L20808 (2006).
14. Shia, R. L., Seigneur, C., Pai, P., Ko, M. \& Sze, N. D. Global simulation of atmospheric mercury concentrations and deposition fluxes. J. Geophys Res Atmos. 104, 23747-23760 (1999).

15. Qureshi A., MacLeod M., Sunderland E., Hungerbühler K. in Environmental Chemistry and Toxicology of Mercury (eds Liu, G. et al.) Ch. 12 (John Wiley \& Sons, Inc., 2011).

16. Pehkonen, S. O. \& Lin, C.-J. Aqueous photochemistry of mercury with organic acids. J. Air Waste Manag. Assoc. 48, 144-150 (1998).

17. Seigneur, C., Vijayaraghavan, K. \& Lohman, K. Atmospheric mercury chemistry: Sensitivity of global model simulations to chemical reactions. J. Geophys Res Atmos. 111, D22306 (2006).

18. Gårdfeldt, K. et al. Evasion of mercury from coastal and open waters of the Atlantic Ocean and the Mediterranean Sea. Atmos. Environ. 37, 73-84 (2003)

19. Lindqvist, O. et al. Mercury in the Swedish environment-recent research on causes, consequences and corrective methods. Water Air Soil Pollut. 55, xi-261 (1991)

20. Strömberg, D., Strömberg, A. \& Wahlgren, U. Relativistic quantum calculations on some mercury sulfide molecules. Water Air Soil Pollut. 56, 681-695 (1991)

21. Wadt, W. R. The electronic structure of $\mathrm{HgCl}_{2}$ and $\mathrm{HgBr}_{2}$ and its relationship to photodissociation. J. Chem. Phys. 72, 2469-2478 (1980).

22. Maya, J. Ultraviolet absorption cross sections of $\mathrm{HgI}_{2}, \mathrm{HgBr}_{2}$, and tin (II) halide vapors. J. Chem. Phys. 67, 4976-4980 (1977).

23. Selin, N.E. Chemical cycling and deposition of atmospheric mercury: global constraints from observations.J. Geophys Res Atmos 112, D02308 (2007).

24. Roxlo, C. \& Mandl, A. Vacuum ultraviolet absorption cross sections for halogen containing molecules. J. Appl. Phys. 51, 2969-2972 (1980).

25. Schimitschek, E., Celto, J. \& Trias, J. A. Mercuric bromide photodissociation laser. Appl. Phys. Lett. 31, 608-610 (1977).

26. Frantom, G., Bletzinger, P. \& Garscadden, A. Measurement of the ultraviolet absorption cross-section of mercuric bromide. Bull. Am. Phys. Soc. 25, 461 (1980).

27. Jiao, Y. \& Dibble, T. S. First kinetic study of the atmospherically important reactions $\mathrm{BrHg}^{\circ}+\mathrm{NO} 2$ and $\mathrm{BrHg}+\mathrm{HOO}$. Phys. Chem. Chem. Phys. 19, 1826-1838 (2017)

28. Erlandson, A. C. \& Cool, T. A. On the regeneration mechanism of $\mathrm{HgBr} / 2$ in $\mathrm{HgBr} / \mathrm{HgBr}_{2}$ dissociation lasers. Chem. Phys. Lett. 96, 685-689 (1983).

29. Whitehurst, C. \& King, T. Emission spectroscopy of mixed photodissociated mercury halides. J. Phys. D. Appl. Phys. 20, 1577 (1987).

30. Wilcomb, B., Burnham, R. \& Djeu, N. UV absorption cross section and fluorescence efficiency of HgBr2. Chem. Phys. Lett. 75, 239-242 (1980).

31. Baker, H. \& Seddon, N. Transient absorption processes in a mercury bromide laser discharge. J. Phys. D. Appl. Phys. 21, 1347 (1988).

32. Schilowitz, A. M. \& Wiesenfeld, J. R. Time-resolved study of mercury atom production and removal following the photolysis of $\mathrm{HgBr}_{2}$ at $193 \mathrm{~nm}$. Chem. Phys. Lett. 89, 438-442 (1982).

33. Travnikov, O. Contribution of the intercontinental atmospheric transport to mercury pollution in the Northern Hemisphere. Atmos. Environ. 39, $7541-7548$ (2005)

34. Travnikov, O. et al. Multi-model study of mercury dispersion in the atmosphere: atmospheric processes and model evaluation. Atmos. Chem. Phys. 17, 5271 (2017)

35. Schuster, P. F. et al. Permafrost stores a globally significant amount of mercury. Geophys. Res. Lett. 45, 1463-1471 (2018).

36. Sitkiewicz, S. P. et al. Ab initio quantum-chemical computations of the electronic states in $\mathrm{HgBr}_{2}$ and IBr: Molecules of interest on the Earth's atmosphere. J. Chem. Phys. 145, 244304 (2016).

37. Finley, J., Malmqvist, P.-Å., Roos, B. O. \& Serrano-Andrés, L. The multi-state CASPT2 method. Chem. Phys. Lett. 288, 299-306 (1998).

38. Roos, B. O., Lindh, R., Malmqvist, P.-A., Veryazov, V. \& Widmark, P.-O. Main group atoms and dimers studied with a new relativistic ANO basis set. J. Phys. Chem. A 108, 2851-2858 (2004).

39. Aquilante, F. et al. Molcas 8: New capabilities for multiconfigurational quantum chemical calculations across the periodic table. J. Comput. Chem. 37, 506-541 (2016)

40. Barbatti, M., Aquino, A. J. \& Lischka, H. The UV absorption of nucleobases: semi-classical ab initio spectra simulations. Phys. Chem. Chem. Phys. 12, 4959-4967 (2010).

41. Crespo-Otero, R. \& Barbatti, M. Spectrum simulation and decomposition with nuclear ensemble: formal derivation and application to benzene, furan and 2phenylfuran. Theor. Chem. Acc. 131, 1237 (2012).

42. Barbatti, $M$. et al. The on-the-fly surface-hopping program system Newton-X Application to ab initio simulation of the nonadiabatic photodynamics of benchmark systems. J. Photochem. Photobiol. A: Chem. 190, 228-240 (2007).

43. Barbatti, M. et al. Newton-X: a surface-hopping program for nonadiabatic molecular dynamics. Wiley Interdiscip. Rev.: Comput. Mol. Sci. 4, 26-33 (2014). 
44. Adamo, C. \& Barone, V. Toward reliable density functional methods without adjustable parameters: The PBE0 model. J. Chem. Phys. 110, 6158-6170 (1999).

45. Andrae, D., Haeussermann, U., Dolg, M., Stoll, H. \& Preuss, H. Energyadjustedab initio pseudopotentials for the second and third row transition elements. Theor. Chem. Acc.: Theory, Comput., Model. (Theor. Chim. Acta) 77, 123-141 (1990).

46. Peterson, K. A., Figgen, D., Goll, E., Stoll, H. \& Dolg, M. Systematically convergent basis sets with relativistic pseudopotentials. II. Small-core pseudopotentials and correlation consistent basis sets for the post-d group 16-18 elements. J. Chem. Phys. 119, 11113-11123 (2003).

47. Weigend, F. \& Ahlrichs, R. Balanced basis sets of split valence, triple zeta valence and quadruple zeta valence quality for $\mathrm{H}$ to $\mathrm{Rn}$ : Design and assessment of accuracy. Phys. Chem. Chem. Phys. 7, 3297-3305 (2005).

48. Frisch, M. et al., Gaussian 09, revision D. 01. (Gaussian, Inc., Wallingford CT, 2009).

49. Ordóñez, C. et al. Bromine and iodine chemistry in a global chemistry-climate model: description and evaluation of very short-lived oceanic sources. Atmos. Chem. Phys. 12, 1423-1447 (2012).

50. Fernandez, R. P., Salawitch, R. J., Kinnison, D. E., Lamarque, J. F. \& SaizLopez, A. Bromine partitioning in the tropical tropopause layer: implications for stratospheric injection. Atmos. Chem. Phys. 14, 13391-13410 (2014).

51. Saiz-Lopez, A. et al. Iodine chemistry in the troposphere and its effect on ozone. Atmos. Chem. Phys. 14, 13119-13143 (2014).

52. Saiz-Lopez, A. et al. Injection of iodine to the stratosphere. Geophys. Res. Lett. 42, 6852-6859 (2015).

53. Prados-Roman, C., Cuevas, C. A., Fernandez, R. P., Kinnison, D. E., Lamarque, J. F. \& Saiz-Lopez, A. A negative feedback between anthropogenic ozone pollution and enhanced ocean emissions of iodine. Atmos. Chem. Phys. 15, 2215-2224 (2015).

54. Gent, P. R. et al. The community climate system model version 4. J. Clim. 24, 4973-4991 (2011).

55. Soerensen, A. L. et al. An improved global model for air-sea exchange of mercury: High concentrations over the North Atlantic. Environ. Sci. Technol. 44, 8574-8580 (2010).

56. Amos, H. M. et al. Gas-particle partitioning of atmospheric Hg (II) and its effect on global mercury deposition. Atmos. Chem. Phys. 12, 591-603 (2012).

57. Schmidt, J.A. et al. Modeling the observed tropospheric $\mathrm{BrO}$ background: Importance of multiphase chemistry and implications for ozone, $\mathrm{OH}$, and mercury. J. Geophys.Res. Atmos 121, 11819-11835 (2016).

58. Eastham, S. D., Weisenstein, D. K. \& Barrett, S. R. Development and evaluation of the unified tropospheric-stratospheric chemistry extension (UCX) for the global chemistry-transport model GEOS-Chem. Atmos. Environ. 89, 52-63 (2014).

59. Bian, H. \& Prather, M. J. Fast-J2: Accurate simulation of stratospheric photolysis in global chemical models. J. Atmos. Chem. 41, 281-296 (2002).

60. Travnikov O. \& Ilyin I. The EMEP/MSC-E mercury modeling system. In Mercury Fate and Transport in the Global Atmosphere (eds Mason R. \& Pirrone N.) 571-587 (Springer, Boston, 2009).

61. Skamarock W. C. et al. A description of the advanced research WRF version 2. NCAR Technical Note, NCAR/TN-468+STR. (National Center For Atmospheric Research, Mesoscale and Microscale Meteorology Div, Boulder, Co, 2005).

62. ECMWF: European Centre for Medium-Range Weather Forecasts (datasets available from http://www.ecmwf.int/en/forecasts/datasetaF).

63. Balabanov, N. B., Shepler, B. C. \& Peterson, K. A. Accurate global potential energy surface and reaction dynamics for the ground state of $\mathrm{HgBr}$. J. Phys. Chem. A 109, 8765-8773 (2005).

64. Donohoue, D. L., Bauer, D., Cossairt, B. \& Hynes, A. J. Temperature and pressure dependent rate coefficients for the reaction of $\mathrm{Hg}$ with $\mathrm{Br}$ and the reaction of $\mathrm{Br}$ with $\mathrm{Br}$ : A pulsed laser photolysis-pulsed laser induced fluorescence study. J. Phys. Chem. A 110, 6623-6632 (2006).

65. Parrella, J. et al. Tropospheric bromine chemistry: implications for present and pre-industrial ozone and mercury. Atmos. Chem. Phys. 12, 6723-6740 (2012).

66. Emmons L. K. et al. Description and evaluation of the Model for Ozone and Related chemical Tracers, version 4 (MOZART-4). (2010).

67. Gårdfeldt, K., Sommar, J., Strömberg, D. \& Feng, X. Oxidation of atomic mercury by hydroxyl radicals and photoinduced decomposition of methylmercury in the aqueous phase. Atmos. Environ. 35, 3039-3047 (2001).
68. Munthe, J. The aqueous oxidation of elemental mercury by ozone. Atmos. Environ. Part A General. Top. 26, 1461-1468 (1992).

69. AMAP/UNEP. Technical Background Report for the Global Mercury Assessment 2013. Arctic Monitoring and Assessment Programme, Oslo, Norway/UNEP ChemicalsBranch, Geneva, Switzerland. vi+263pp (2013).

70. Enrico, M. et al. Atmospheric mercury transfer to peat bogs dominated by gaseous elemental mercury dry deposition. Environ. Sci. Technol. 50, 2405-2412 (2016)

\section{Acknowledgements}

This work was supported by the Consejo Superior de Investigaciones Científicas (CSIC) Spain. The National Center for Atmospheric Research (NCAR) is funded by the National Science Foundation (NSF). Computing resources were provided by the Climate Simulation Laboratory at NCAR's Computational and Information Systems Laboratory (CISL), sponsored by the NSF, provided computing resources. The CESM project (which includes CAM-Chem) is supported by the NSF and the office of Science (BER) of the US Department of Energy. This study has received funding from the European Research Council Executive Agency under the European Union's Horizon 2020 Research and innovation programme (Projects 'ERC-2016-COG 726349 CLIMAHAL' to A.S.L. and 'ERC-2010-STG 258537' to J.E.S.), and from H2020 ERA-PLANET 689443. S.P.S. acknowledges the Basque Government for funding through a PhD fellowship (PRE 2017 1 0403). D.R.S. is thankful to the Spanish Ministerio de Economía y Competitividad (MINECO) (Projects CTQ2017-87054-C2-2-P, RYC-2015-19234 grant, and Unit of Excellence María de Maeztu MDM-2015-0538). J.M.O-E. is grateful to program "Salvador de Madariaga” Project No. PRX17/00488 (Ministerio de Educación, Cultura y Deporte). We thank the UMS 831 Pic du Midi Observatory team for help with rainwater sampling and Franck Gilbert for use of the solar simulator.

\section{Author contributions}

A.S.-L and J.E.S conceived the experiments. S.P.S. and D.R-S. performed the quantumchemical simulations. C.A.C and D.E.K. performed the global photolysis rate calculations. M.J. and Y.X. conducted the aqueous photoreduction experiments. C.P.T., E.M.S. D.J.J., and O.T. performed the mercury chemical transport model simulations. A.S.-L., S.P.S., D.R-S. J.M.O., J.Z.D., R.N., J.M.C.P., C.A.C., D.E.K., F.W., D.R., A.U.A., J.E.S., C.P.T., E.M.S., D.J.J., and O.T. analysed and interpreted both the quantum-chemical and atmospheric results. All authors contributed to paper writing.

\section{Additional information}

Supplementary Information accompanies this paper at https://doi.org/10.1038/s41467018-07075-3.

Competing interests: The authors declare no competing interests.

Reprints and permission information is available online at http://npg.nature.com/ reprintsandpermissions/

Publisher's note: Springer Nature remains neutral with regard to jurisdictional claims in published maps and institutional affiliations.

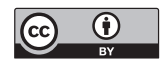

Open Access This article is licensed under a Creative Commons Attribution 4.0 International License, which permits use, sharing, adaptation, distribution and reproduction in any medium or format, as long as you give appropriate credit to the original author(s) and the source, provide a link to the Creative Commons license, and indicate if changes were made. The images or other third party material in this article are included in the article's Creative Commons license, unless indicated otherwise in a credit line to the material. If material is not included in the article's Creative Commons license and your intended use is not permitted by statutory regulation or exceeds the permitted use, you will need to obtain permission directly from the copyright holder. To view a copy of this license, visit http://creativecommons.org/ licenses/by/4.0/.

(C) The Author(s) 2018 